\title{
Prevalence of posttraumatic stress disorder among Syrian refugees in Domiz camp-Duhok city
}

\begin{tabular}{cc}
\hline Yousif Ali Yaseen* & Ghazwan Rasho Khedir** \\
\hline & Abstract
\end{tabular}

Background and Objective: Posttraumatic stress disorder is a psychiatric disorder that occurs in people who have experienced or witnessed a life threatening event. This study aimed to assess the prevalence and risk factors of posttraumatic stress disorder among Syrian refugees in Domiz Camp in Duhok City.

Methods: Through a cross-sectional study, 500 Syrian refugees were interviewed using the Posttraumatic Stress Disorder Checklist Civilian version (PCL-C) which was translated into the Arabic language. The sample was selected randomly. Refugees who were 20 years old and older and from both sexes were included, and those with severe medical diseases and serious psychiatric diseases (psychotic conditions and mentally retarded) were excluded. Data analysis had been done using the statistical package for the social sciences.

Results: The prevalence of posttraumatic stress disorder was $25.2 \%$ (126 cases). There was statistically significant association between the occurrence of PTSD and some variables such as female $(28.7 \% ; P=0.003)$, housewife $(28.5 \% ; P=0.012)$ and nearly significant association with the positive family psychiatric history $(42.9 \% ; P=0.057)$. The results showed no statistically significant association between the occurrence of posttraumatic stress disorder and other variables such as age $(P=0.106)$, educational level $(P=0.148)$, marital status $(P=0.210)$ and patient past psychiatric history $(P=0.164)$.

Conclusions: The high prevalence of posttraumatic stress disorder among the Syrian refugees $(25.2 \%)$ makes it one of the most important mental health issues that should be taken into consideration. The females, housewives and those with a positive family psychiatric history are regarded among high risk groups. Early detection and better management of those groups may be of high priority.

Keyword: Posttraumatic Stress Disorder; Syrian refugees; Domiz Camp; Duhok City.

\section{Introduction}

Posttraumatic stress disorder (PTSD) is a psychiatric disorder that can occur after the person's exposure or witness of life-threatening events such as war, military combat, attacks of terrorism, severe accidents, physical violence, rape, etc. ${ }^{1}$ PTSD is a kind of anxiety disorder which can occur directly after an event or any time later that lead to negative thoughts about that painful and stressful event. ${ }^{2}$ The nature of stress is variable, an event which can produce stress in someone may be normal for another, and an event that may produce stress at one time and place for one person may not be so for that person at another time and place. $^{3}$ PTSD was officially recognized in 1980 after the third edition of the Diagnostic and Statistical Manual of Mental Disorders (DSM-III) appeared, and American Psychiatric Association added PTSD to it. PTSD refers to as soldier's heart, shell shock, war neurosis, gross stress reaction and adjustment reaction of adult life. ${ }^{4}$ To assess a patient with PTSD, it needs to identify the pre-morbid history of the patient, available coping resources and

* Department of Psychiatry, College of Medicine, University of Duhok, Duhok, Iraq.

** Directorate General of Health in Duhok, Duhok, Iraq. 
measuring resources to assess a variety of potentially traumatizing events overall developmental period, including neglect, separation, emotional abuse, sexual abuse, witnessing other traumas and history of alcohol and substance abuse. ${ }^{5}$ The duration of the traumatic event is significant as an indicator for the degree of exposure, and the evaluator needs to ask about the "fear" that consider the aspect of the painful, traumatic experience, particularly when threaten the life. ${ }^{6}$ There is an association between the severity of mental health problems and exposure to the events such as injuries, wars, witnessing the death and torture. ${ }^{7}$ Patients with PTSD have abnormal levels of key hormones that contribute to the response to the stress, and when they are in dangerous stage or a serious condition, they produce high levels of natural hormones like opiates, which reduce the severity of pain temporarily. ${ }^{8}$ The lifetime incidence of PTSD is estimated to be $9-15 \%$ and the lifetime prevalence of PTSD is estimated to be about $8 \%$ of the general population, while an additional $5-15 \%$ may experience subclinical forms of the disorder. ${ }^{9}$ Compared with the general population, the prevalence of PTSD appears lower among the elderly. ${ }^{10}$ This study aimed to assess the prevalence and risk factors of PTSD among Syrian refugees in Domiz Camp in Duhok City.

\section{Methods}

A cross-sectional study was carried out from June 2014 - June 2015 to assess PTSD among Syrian refugees in Domiz Camp in Duhok City which is the place where Syrian refugees live since March 2011 after the beginning of the Syrian civil war. The subjects of the study consisted of (500) individuals from Syrian refugees lived in Domiz Camp, they were selected randomly. The verbal consent had been taken from all participants before their involvement. Furthermore, before starting the study, the formal administrative approval was obtained from related institutions: Faculty of Medical Sciences/ University of Duhok, General Directorate of the Health in Duhok, Directorate of Domiz Camp and Directorate of Security in Domiz Camp. The refugees who were 20 years and older, and of both genders were included in this study. The severe medically ill patients and severe psychiatric cases (psychotic conditions and mentally retarded) were excluded. Data of the study were gathered through the use of Posttraumatic Stress Disorder Checklist Civilian version (PCL-C). This type of measure asks about symptoms related to PTSD for all people who have been exposed to stressful experiences, and it was translated into the Arabic language to be easier for participants. Although the tool is a self-administered questionnaire, it was applied through an interview in this study. PTSD checklist was used for diagnosis, which depends on the criteria of DSM-IV, it comprises (17 items) that corresponds to the key symptoms of PTSD. The socio-demographic data of the sample were collected through a form prepared for the study. Data analysis had been done through the usage of the statistical package for the social sciences (version 19). Pearson Chi Square test was used to assess the association between two categorical variables. When the expected count of more than $20 \%$ of the cells of the table was less than 5, Fisher's Exact test was used. A $P$ value of less than 0.05 was considered statistically significant.

\section{Results}

The association of socio-demographic characteristic to PTSD (Table 2):

The results showed that the prevalence of PTSD was significantly higher among females $(28.7 \%)$ than the prevalence $(15.7 \%)$ among males $(P=0.003)$. Statistically, no significant association was detected between age and PTSD $(P=0.106)$, despite that (the highest prevalence $(36.5 \%)$ was in the age group 40-49 years. Regarding the educational level, the highest percentage of 
participants having PTSD were from primary educational level $(30.4 \%)$, but no significant association was found between PTSD and educational background $(P=$ 0.148). Similarly, no significant association was found between marital status and PTSD $(P=0.210)$, despite that the prevalence was $100 \%$ among widowed (the number of widowed was one only). Concerning the occupation, the prevalence was $28.5 \%$ among housewives, while the lowest prevalence (12.9\%) was among the self-employed. Statistically, the result showed a significant association between PTSD and occupation $(P=0.012)$.

Table 1: Prevalence of PTSD among the studied sample.

\begin{tabular}{lcc}
\hline PTSD & Frequency & Percent \\
\hline Positive & 126 & 25.2 \\
Negative & 374 & 74.8 \\
Total & $\mathbf{5 0 0}$ & $\mathbf{1 0 0}$ \\
\hline
\end{tabular}

Table 2: The association of socio-demographic characteristic to PTSD.

\begin{tabular}{lcccc}
\hline Variables & $\begin{array}{c}\text { Positive } \\
\text { No. (\%) }\end{array}$ & $\begin{array}{c}\text { Negative } \\
\text { No. (\%) }\end{array}$ & $\begin{array}{c}\text { Total } \\
\text { No. (\%) }\end{array}$ & P value \\
\hline Gender & & & & \\
Female & $105(28.7)$ & $261(71.3)$ & $366(100)$ & $0.003^{*}$ \\
Male & $21(15.7)$ & $113(84.3)$ & $134(100)$ & \\
Age (Years) & & & & \\
$20-29$ & $34(19.5)$ & $140(80.5)$ & $174(100)$ & \\
$30-39$ & $46(25.1)$ & $137(74.9)$ & $183(100)$ & \\
$40-49$ & $31(36.5)$ & $54(63.5)$ & $85(100)$ & $0.106^{* *}$ \\
$50-59$ & $10(26.3)$ & $28(73.7)$ & $38(100)$ & \\
$\geq 60$ & $5(25)$ & $15(75)$ & $20(100)$ & \\
Educational level & & & & \\
Illiterate & & $159(74)$ & $215(100)$ & \\
Read \& write & $56(26)$ & $59(85.5)$ & $69(100)$ & \\
Primary & $10(14.5)$ & $64(69.6)$ & $92(100)$ & $0.0148^{*}$ \\
Secondary & $28(30.4)$ & $66(71.7)$ & $92(100)$ & \\
University & $26(28.3)$ & $26(81.3)$ & $32(100)$ & \\
\hline${ }^{*}$ Pearson Chi-Square & $6(18.8)$ & & & \\
\hline & & & & \\
\hline
\end{tabular}




\section{Discussion}

The difficult and complicated situation in which the Syrian families live in Domiz Camp in Duhok City, Kurdistan Region of Iraq with the short and long-term social and psychological impacts encouraged us to do field study about the prevalence and associated risk factors of PTSD among Syrian refugees especially within the adult age group to have accurate and visible results. The prevalence rate of PTSD among participants in this study $(25.2 \%)$ appeared close (to a certain extent) to the result of Turkish study conducted by Alpak et al in 2014 about PTSD among Syrian Refugees, in which the frequency of PTSD was $33.5 \% .{ }^{11}$ The difference in the percentage of PTSD between both studies might be due to the early escape of refugees from Syria to Duhok City before the intensification of the war there, in addition to the difference in the sample size in both studies. While the result is very close to Espie et al. study done among Palestinian from 2005-2008, in which the prevalence of PTSD was $23.2 \%{ }^{12}$ According to the National Vietnam Veterans Readjustment Study (NVVRS), $30 \%$ of men develop full-blown PTSD after having served in the war. ${ }^{9}$ There was no statistically significant association in relation to the different age groups. The result goes with the result of a study conducted by Sana and Khattak in Pakistan in 2014. ${ }^{13}$ Sadock et al. stated that PTSD could appear at any age, it is most prevalent in young adults, because they tend to be more exposed to precipitating situations. ${ }^{9}$ In this study females were much more affected by PTSD than males, this agrees with the results of Alpak et al. study and Gradus study (conducted among Americans in 2013). ${ }^{11,14}$ Higher risk of PTSD in females is primarily due to a particular vulnerability to assaultive violence which is more threatening and injurious to females. ${ }^{15}$ The relationship between prevalence of PTSD and educational background appeared statistically not significant, and the result is compatible with the result of Sana and Khattakstudy. ${ }^{13}$ However, a lower level of education is regarded as a risk factor for PTSD in Breslau et al. study. ${ }^{16}$ The sample sizes, the difference of the type of the traumatic events and selected age group between the two studies could explain why the educational background is not a risk factor for PTSD in this study. The majority of PTSD cases were housewives. This result appeared statistically significant. A majority of the participants in this study were females and the majority of them were housewives this could explain this significance. This study showed no significant relationship between marital status and PTSD, While Magruder et al study showed that PTSD being highest for previously married and lowest for never married veterans. ${ }^{17}$ This could be explained by methodological differences between the two studies, especially regarding populations studied and this might have affected the results. The result showed that statistically no significant relationship between the patient psychiatric history and PTSD, while previous psychiatric history was considered a risk factor of PTSD according to Alpak et al. and Farhood and Dimassi. ${ }^{11,18}$ This difference could be explained by way of determining personal psychiatric history (in this study, the researcher depended on clear evidence like medical documents: medical reports, treatment sheets and proven psychiatric consultation) this may have affected the number of positive cases. The result showed a nearly statistically significant relationship between the family psychiatric history and PTSD. This result is consistent with the work of Alpak et al., Grinage and Brewin et al. ${ }^{11,19}$, 20 This result suggests that a positive family history of psychiatric disorders is a constant risk factor for the development of PTSD.

\section{Conclusion}

The prevalence of PTSD among Syrian Refugees in Domiz Camp in Duhok City 
was high. It was more prevalent among females, housewives and those with a family history of psychiatric disorders. Although PTSD was more prevalent among 40-49 years age group, primary education level, married and those with positive personal psychiatric history, but statistically the relation was not significant. The PTSD appears as one of the important mental health issues that should be taken into consideration among Syrian Refuges in Domiz Camp.

\section{Competing interests}

The authors declare that they have no competing interests.

\section{References}

1. Kozarić-Kovačić D, Pivac N. Novel Approaches to the Diagnosis and Treatment of Posttraumatic Stress Disorder. In: Begeç S. The Integration and Management of Traumatized People after Terrorist Attacks [e-book]. Amsterdam: IOS Press; 2007.

2. Reichert J, Bostwick L. Post-traumatic stress disorder and victimization among female prisoners in Illinois [e-book]. Chicago: Illinois Criminal Justice Information Authority; 2010.

3. Smeltzer S, Bare B. Brunner and Suddarth's Textbook of Medical-Surgical Nursing. $9^{\text {th }}$ ed. Philadelphia: Lippincott Williams \& Wilkins; 2000.

4. Kinchin D. Post Traumatic Stress Disorder: The Invisible Injury [e-book]. $2^{\text {nd }}$ ed. Oxfordshire: Wessex press; 2005.

5. Kolk BAV. The assessment and treatment of complex PTSD. In: Yehuda R. Traumatic Stress. Arlington VA: American Psychiatric Press; 2001.

6. Adshead G. Psychological therapies for posttraumatic stress disorder. Br J Psychiatry 2000; 177(2):144-8.

7. Papageorgiou $V$, Frangou-Garunovic A, Lordanidou R, Yule W, Smith P, Vostanis P. War trauma and psychopathology in Bosnian refugee children. Eur Child Adolesc Psychiatry 2000; 9(2):84-90.

8. Coppola DP. Introduction to International Disaster Management [e-book]. $2^{\text {nd }}$ ed. Burlington: Elsevier Inc; 2011.

9. Sadock BJ, Sadock VA, Ruiz P. Kaplan and Sadock's Synopsis of Psychiatry: Behavioral Sciences/Clinical Psychiatry. $11^{\text {th }}$ ed. Philadelphia: Wolters Kluwer; 2015.

10. American Psychiatric Association. Diagnostic and Statistical Manual of Mental Disorders. $5^{\text {th }}$ ed. Arlington, VA: American Psychiatric Association; 2013.
11. Alpak G, Unal A, Bulbul F, Sagaltici E, Bez Y, Altindag $A$, et al. Post-traumatic stress disorder among Syrian refugees in Turkey: A cross-sectional study. Int J Psychiatry Clin Pract 2015; 19(1):45-50.

12. Espie E, Gaboulad V, Baubet T, Casas G, Mouchenik Y, Yun O, et al. Trauma-related psychological disorders among Palestinian children and adults in Gaza and West Bank, 2005-2008. Int J Ment Health Syst 2009; 3:21.

13. Sana R, Khattak SUR. Prevalence of Posttraumatic Stress Disorder in flood affected population of Banda Sheikh Ismail, District Nowshera. J Postgrad Med Inst 2014; 28(1):2732.

14. Gradus JL. Epidemiology of PTSD. In: U.S. Department of Veterans Affairs. PTSD: National Center for Post-Traumatic Stress Disorder. USA: The Department; 2013.

15. Breslau N, Chilcoat HD, Kessler RC, Peterson EL, Lucia VC. Vulnerability to assaultive violence: further specification of the sex difference in post-traumatic stress disorder. Psychol Med 1999; 156 (6):902-7.

16. Breslau N, Davis GC, Andreski P. Risk factors for PTSD-related traumatic events: A prospective analysis. AmJ Psychiatry 1995; 152(4):529-35.

17. Magruder KM, Frueh BC, Knapp RG, Johnson MR, Vaughan JA, Carson TC, et al. PTSD symptoms, demographic characteristics, and functional status among veterans treated in VA primary care clinics. J Trauma Stress 2004; 17(4):293-301.

18. Farhood L, Dimassi $H$. Prevalence and predictors for post-traumatic stress disorder, depression and general health in a population from six villages in South Lebanon. Soc Psychiatry Psychiatric Epidemiology 2012; 47 (4):639-49.

19. Grinage BD. Diagnosis and Management of Post -traumatic Stress Disorder. Am Fam Phys 2003; 68(12):2401-9.

20. Brewin CR, Andrews B, Valentine JD. Meta-Analysis of Risk Factors for Posttraumatic Stress Disorder in Trauma-Exposed Adults. J Consult Clin Psychol 2000; 68(5):748-66. 